\title{
Diet, physical activity and cognitive impairment among elders: the EPIC-Greece cohort (European Prospective Investigation into Cancer and Nutrition)
}

\author{
T Psaltopoulou ${ }^{1}$, A Kyrozis ${ }^{2, *}$, P Stathopoulos ${ }^{1}$, D Trichopoulos ${ }^{3,4}$, D Vassilopoulos ${ }^{2}$ \\ A Trichopoulou 1,4 \\ 'Department of Hygiene and Epidemiology, University of Athens Medical School, 75 Mikras Asias Street, \\ GR-1 1527 Athens, Greece: ${ }^{2}$ Department of Neurology, Eginition Hospital, University of Athens Medical School, \\ 72 Vas. Sofias Avenue, GR-1 1528 Athens, Greece: ${ }^{3}$ Department of Epidemiology, Harvard School of Public \\ Health, 677 Huntington Avenue, Boston, MA 02115, USA: ${ }^{4}$ Hellenic Health Foundation, 10-12 Tetrapoleos, \\ GR-1 1527 Athens, Greece
}

Submitted 21 May 2007: Accepted 8 0ctober 2007: First published online 21 January 2008

\begin{abstract}
Objectives: To identify dietary and lifestyle variables that may affect cognitive function in the elderly.

Design: Population-based prospective cohort study.

Setting: General community residing in Athens and the surrounding Attica region of Greece.

Subjects: A total of 732 men and women, 60 years or older, participating in the EPIC-Greece cohort (European Prospective Investigation into Cancer and Nutrition) and residing in the Attica region had sociodemographic, anthropometric, medical, dietary and lifestyle variables ascertained at enrolment (1993-1999). Six to 13 years later, cognitive function was evaluated through the Mini-Mental State Examination (MMSE) score and affective state through the Geriatric Depression Scale (GDS).

Results: MMSE score was positively associated with years of formal education, height and physical activity and inversely with age, diabetes mellitus and GDS score $(P<0.05$ for all). Among dietary variables, intake of PUFA was inversely associated with cognitive function and this association was largely accounted for by a similar association with seed oils. Adherence to the Mediterranean diet, as well as intake of olive oil, MUFA and SFA exhibited weakly positive but not significant associations. Conclusion: Physical activity and early life factors as reflected in height are significant predictors of cognitive function in the elderly. Seed oil consumption may adversely affect cognition, whereas other nutritional factors do not appear to have a quantitatively large effect.
\end{abstract}

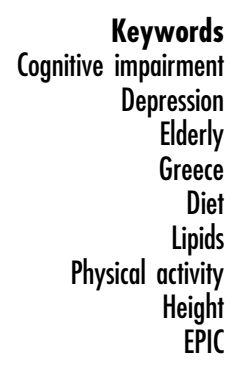

Cognitive impairment is a common cause of morbidity in the elderly ${ }^{(1)}$. Its most severe form, dementia, is characterized by dependency in everyday activities and reduced quality of life, poses a great burden on society and constitutes an important predisposing factor for mortality $^{(2)}$. The prevalence of cognitive impairment has increased in recent years, owing mostly to increased life expectancy and the concomitant increase in the proportion of elderly people ${ }^{(3)}$.

Since currently available treatment for cognitive impairment has limited effectiveness, finding ways to prevent or delay its onset is regarded as a public health priority. Alzheimer's disease, a neurodegenerative condition of complex and not well understood pathophysiology, is the most frequent cause of dementia ${ }^{(4,5)}$.
Microvascular cerebral disease is the second most common cause, but exact percentages are difficult to assess because a significant portion of dementia cases have mixed clinical and imaging characteristics of Alzheimer's and microvascular cerebral disease, thus posing diagnostic uncertainty. In fact, Alzheimer's and microvascular disease may overlap pathogenetically, a hypothesis supported by epidemiological evidence suggesting that well-recognized risk factors for atherosclerotic disease, including hypertension, diabetes, smoking and hyperlipidaemia, play a role not only in vascular dementia but also in Alzheimer's disease as well ${ }^{(6-10)}$.

For epidemiological purposes, cognitive impairment can be assessed either by establishing specific diagnoses or by quantifying cognitive function with appropriate scales. 
An advantage of specific diagnostic classification is that it may facilitate an aetiological association. A disadvantage is that differentiation among different dementing conditions is often not straightforward. Cognitive assessment scales generally do not distinguish among causes of dementia but are very useful for clinical and public health purposes. The Mini-Mental State Examination (MMSE) is a quantitative indicator of cognitive function widely used clinically and epidemiologically, and has been consistently validated as a good indicator of a person's mental capacity for everyday activities, both internationally ${ }^{(11-14)}$ and in Greece ${ }^{(15)}$. Since cognitive impairment has a complex relationship with depression in the elderly, assessment of affective state usually accompanies cognitive status assessment, using scales such as the Geriatric Depression Scale (GDS). The GDS has been validated in several populations ${ }^{(16-19)}$, as well as in Greece ${ }^{(20)}$.

In order to study the possible role of several dietary variables, such as the Mediterranean diet and different groups of lipids, and lifestyle characteristics in the cognitive status of elderly in the Greek population, we have undertaken a study using an important resource, the EPIC-Greece cohort. This cohort allows the evaluation of cognitive function several years after assessment of potentially important predictor variables, bypassing several problems that would have been generated by cross-sectional assessment of exposures and outcome.

\section{Methods}

\section{Study participants}

The initial study sample consisted of 28572 volunteers, women and men aged 20-86 years, recruited between 1993 and 1999 from all regions of Greece, in order to participate in the Greek component of the European Prospective Investigation into Cancer and Nutrition

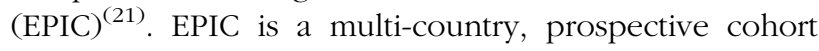
study, conducted in twenty-two research centres across ten European countries and coordinated by the International Agency for Research on Cancer. The aims of EPIC are the elucidation of the role of biological, dietary, lifestyle and environmental factors in the aetiology of chronic diseases ${ }^{(22,23)}$. Cancer studies are jointly published by the EPIC consortium, while investigations with different objectives are also undertaken by individual countries. The present study, termed ILIDA (from the Greek words for elders and diet), is nested within the EPIC-Greece cohort. Inclusion criteria were residence in the Attica region that surrounds and includes Athens and age at enrolment of 60 years or more. There were 1225 eligible study participants. Beginning in March 2004, subjects eligible for the ILIDA project were invited by telephone for assessment of cognitive functioning and emotional status. Of them, 816 agreed to participate, 165 refused, 151 had died during the course of their follow-up, twenty-five had a new permanent residence outside Attica and another sixty-eight could not be traced. Information on one or more of the dietary, anthropometric or lifestyle variables was missing in seventy-one of the 816 volunteers and these were excluded from the analysis. Furthermore, thirteen subjects who reported a stroke at baseline were also excluded. Thus, 732 participants were included in the final analyses. Subjects were tested by a team of specially trained staff, comprising a nurse, a social worker and a physician. The participants underwent the neuropsychiatric tests $6 \cdot 4$ to 12.6 years after enrolment in the EPIC-Greece cohort (median $8 \cdot 0$ years) .

All procedures were in accordance with the Helsinki Declaration on Human Rights of 1975 as revised in 1983; all participants provided written informed consent before enrolment in the EPIC study and again before enrolment in the ILIDA study. The study protocol was approved by the University of Athens Medical School.

\section{Data on diet and energy intake}

An interviewer-administered FFQ including approximately 150 foods and beverages commonly consumed in Greece was used to assess dietary intake ${ }^{(24)}$. The interview focused on the year before enrolment, to accommodate seasonal variation, but is likely to adequately reflect the diet during several years preceding enrolment ${ }^{(25,26)}$. The questionnaire was validated during the pilot phase of the EPIC-Greece study ${ }^{(24)}$. Nutrient intakes were calculated with the use of a food composition database that has been modified to accommodate the special characteristics of the Greek diet ${ }^{(27)}$.

A gradient of adherence to the traditional Greek Mediterranean diet was constructed from nine nutritional components. A value of 0 or 1 was assigned to each of the nine components, using as cut-off values the sex-specific medians among the participants ${ }^{(21)}$. For each of the five presumed beneficial components (vegetables, legumes, fruit and nuts, cereals, fish), subjects were assigned a value of 0 if consumption was below the median and a value of 1 otherwise. In contrast, for each of the two presumed detrimental components (meat and meat products, dairy products), subjects were assigned a value of 1 if consumption was below the median and a value of 0 otherwise. For ethanol, a value of 1 was given to men who consumed quantities of ethanol from 10 to $<50 \mathrm{~g} / \mathrm{d}$, whereas for women the corresponding cut-offs were 5 and $25 \mathrm{~g} / \mathrm{d}$. For lipid intake, the ratio of MUFA to SFA was used; those at or above the median scored 1 and those below the median scored 0. Thus, a 10-point Mediterranean diet score was constructed that could take a value from 0 (minimal adherence) to 9 (maximal adherence). When individually considered, alcohol, MUFA, PUFA, olive oil, seed oil and fish were all expressed in $\mathrm{g} / \mathrm{d}$. Total energy intake was calculated in $\mathrm{MJ} / \mathrm{d}(\mathrm{kcal} / \mathrm{d})^{(28)}$. 


\section{Lifestyle, antbropometric and medical variables}

The frequency and duration of participation in occupational and leisure-time physical activities were recorded in the questionnaire ${ }^{(29)}$ and allowed the calculation of a metabolic equivalent index (MET value) to each activity (household, professional, sporting and other activities) ${ }^{(30)}$ and eventually an overall MET $\times \mathrm{h}$ sum, which indicates the amount of energy per kilogram of body weight expended during an average day by each participant. Standard interviewing procedures were used to assess baseline sociodemographic, medical and lifestyle characteristics, such as age, years of schooling (as an indicator of socio-economic status), marital status and tobacco smoking. Standard measuring procedures were also used to assess anthropometric characteristics, with subjects wearing light clothing, no restrictive underwear and no shoes. Body weight was measured to the nearest $100 \mathrm{~g}$, and height was measured to the nearest centimetre. BMI was then calculated as the ratio of weight in kilograms to the square of height in metres. Participants were requested to complete the MMSE and GDS questionnaires. The MMSE is a widely used questionnaire to screen for cognitive disorders in epidemiological studies; it consists of thirty questions that assess orientation, attention, immediate and short-term recall, language, and the ability to follow simple verbal and written commands, providing a score that places the individual on a scale of cognitive function from 0 (worst) to 30 (best) ${ }^{(31,32)}$. MMSE has been validated in Greece ${ }^{(15)}$. The GDS is a basic screening measure for depression in older adults. The higher score in the scale reflects the severity of the depression; it takes values from 0 (absence of depression) to 15 (serious depression) $^{(20)}$.

\section{Statistical analysis}

For descriptive statistics, distributions of study participants at enrolment by nutritional and non-nutritional variables, as well as MMSE and GDS scores, were examined separately for men and women. To test for possible associations of MMSE score with dietary and lifestyle parameters, multivariate linear regression analysis was used. In each model, independent variables included one dietary parameter of interest, as well as lifestyle parameters and potential confounders. In the prototypical model, linear regressions were performed of MMSE score $v$. gender (male, female), age (continuously, expressed in 5-year increments), marital status (cohabiting with partner $v$. alone), years of education (continuously, expressed in 3-year increments), height (continuously, expressed in $5 \mathrm{~cm}$ increments), BMI (continuously, in $1 \mathrm{~kg} / \mathrm{m}^{2}$ increments), physical activity (continuously, in $3 \mathrm{MET} \times \mathrm{h}$ increments), smoking (ever $v$. never smokers), alcohol intake (categorically, in categories of low, moderate and high intake; moderate intake between 10 and $29.99 \mathrm{~g}$ ethanol/d), hypertension (no, yes; hypertension defined as systolic blood pressure $\geq 140 \mathrm{mmHg}$ and/or diastolic blood pressure $\geq 90 \mathrm{mmHg}$ and/or under antihypertensive treatment), diabetes mellitus (no, yes; self-report of medically diagnosed diabetes), GDS (continuously, in 1-point increments), energy intake (continuously, in increments of $418 \mathrm{~kJ}(100 \mathrm{kcal}) / \mathrm{d})$ and Mediterranean diet score (continuously, in 1-point increments). In additional multiple linear regression models, the Mediterranean diet score was alternatively (one at a time) substituted with SFA, MUFA, PUFA, olive oil, seed oils (mostly corn oil and sunflower oil) and fish plus seafood (all in 1 SD increments). Controlling for energy intake, a mandatory measure in nutritional epidemiology ${ }^{(28)}$, was implemented by including energy daily intake as a variable in all linear regression models.

All analyses were performed using the Intercooled STATA statistical software package version 8.0 for Windows (Stata Corp., College Station, TX, USA).

\section{Results}

Table 1 shows the distribution of the 732 study participants by sociodemographic, anthropometric, medical and lifestyle variables, as well as performance on the GDS and the MMSE stratified by gender. The table reflects well-known patterns in the Greek population constrained by the sampling criteria. Notable observations include the high frequency of smoking among men, the high prevalence of hypertension overall and higher physical activity among women. A substantial fraction of study participants, particularly women, have manifestations indicative of mild depression. With respect to MMSE score, more women than men scored lower than 24, but these univariate characteristics are not directly interpretable because women had lower average educational level.

Table 2 shows mean and standard deviation of daily intake of energy and selected nutritional components by gender. As expected, energy intake was higher among men than among women, but there was no substantial gender difference in the contribution of the indicated nutritional components. Mediterranean diet score was slightly higher among men than among women.

Table 3 presents multiple regression-derived, mutually adjusted, differences in mean score on the MMSE per specified differences in possible predictor variables at enrolment. There were no significant differences with respect to gender, alcohol intake, tobacco smoking or BMI. In contrast, advancing age was inversely associated with MMSE score, whereas years of formal education were positively associated with the score. As expected, the performance of diabetics on the MMSE was slightly inferior, whereas the deficit among hypertensives was not statistically significant. Elderly living alone had slightly lower MMSE score in comparison to those cohabiting, although the difference was not statistically significant. There was a weak, but nevertheless statistically significant 
Table 1 Distribution of the 732 study participants $(257$ men and 475 women) by gender as well as selected sociodemographic, anthropometric, lifestyle and medical variables: EPIC-Greece cohort

\begin{tabular}{|c|c|c|c|c|}
\hline \multirow[b]{2}{*}{ Variable } & \multicolumn{2}{|c|}{ Men } & \multicolumn{2}{|c|}{ Women } \\
\hline & $n$ & $\%$ & $n$ & $\%$ \\
\hline \multicolumn{5}{|l|}{ Age (years) } \\
\hline $60-64$ & 82 & $31 \cdot 9$ & 214 & $45 \cdot 0$ \\
\hline $65-69$ & 90 & $35 \cdot 0$ & 153 & $32 \cdot 3$ \\
\hline$\geq 70$ & 85 & $33 \cdot 1$ & 108 & $22 \cdot 7$ \\
\hline \multicolumn{5}{|l|}{ Marital status } \\
\hline Currently married or cohabiting & 241 & $93 \cdot 8$ & 299 & $62 \cdot 9$ \\
\hline Alone & 16 & $6 \cdot 2$ & 176 & $37 \cdot 1$ \\
\hline \multicolumn{5}{|l|}{ Education (years) } \\
\hline $0-5$ & 30 & $11 \cdot 7$ & 142 & $29 \cdot 9$ \\
\hline $6-11$ & 142 & $55 \cdot 2$ & 194 & $40 \cdot 8$ \\
\hline 12 & 34 & $13 \cdot 2$ & 93 & $19 \cdot 6$ \\
\hline$\geq 13$ & 51 & $19 \cdot 9$ & 46 & $9 \cdot 7$ \\
\hline \multicolumn{5}{|l|}{ Height $(\mathrm{cm})$} \\
\hline$\leq 149 \cdot 9$ & 4 & $1 \cdot 6$ & 229 & $48 \cdot 2$ \\
\hline $155 \cdot 0-159 \cdot 9$ & 18 & $7 \cdot 0$ & 129 & $27 \cdot 2$ \\
\hline $160 \cdot 0-164 \cdot 9$ & 64 & $24 \cdot 9$ & 87 & $18 \cdot 3$ \\
\hline $165 \cdot 0-169 \cdot 9$ & 74 & $28 \cdot 8$ & 23 & $4 \cdot 8$ \\
\hline$\geq 170 \cdot 0$ & 97 & $37 \cdot 7$ & 7 & $1 \cdot 5$ \\
\hline \multicolumn{5}{|l|}{ BMI $\left(\mathrm{kg} / \mathrm{m}^{2}\right)$} \\
\hline$\leq 24.99$ & 32 & $12 \cdot 4$ & 80 & $16 \cdot 9$ \\
\hline $25 \cdot 00-29 \cdot 99$ & 138 & $53 \cdot 7$ & 189 & $39 \cdot 6$ \\
\hline$\geq 30 \cdot 00$ & 87 & 33.9 & 206 & $43 \cdot 5$ \\
\hline \multicolumn{5}{|l|}{ Physical activity $(\mathrm{MET} \times \mathrm{h} / \mathrm{d})$} \\
\hline$\leq 29.99$ & 95 & $37 \cdot 0$ & 60 & $12 \cdot 6$ \\
\hline $30 \cdot 00-31.99$ & 60 & $23 \cdot 3$ & 93 & $19 \cdot 6$ \\
\hline $32 \cdot 00-33.99$ & 56 & $21 \cdot 8$ & 122 & $25 \cdot 7$ \\
\hline $34 \cdot 00-36.99$ & 29 & $11 \cdot 3$ & 131 & $27 \cdot 6$ \\
\hline$\geq 37 \cdot 00$ & 17 & $6 \cdot 6$ & 69 & $14 \cdot 5$ \\
\hline \multicolumn{5}{|l|}{ Smoking } \\
\hline Never smoked habitually & 78 & $30 \cdot 4$ & 352 & $74 \cdot 1$ \\
\hline Current or ex-smoker & 179 & $69 \cdot 6$ & 123 & $25 \cdot 9$ \\
\hline \multicolumn{5}{|l|}{ Alcohol $(g / d)$} \\
\hline$\leq 9.99$ & 152 & $59 \cdot 2$ & 440 & $92 \cdot 6$ \\
\hline $10 \cdot 00-29 \cdot 99$ & 80 & $31 \cdot 1$ & 31 & $6 \cdot 5$ \\
\hline$\geq 30 \cdot 00$ & 25 & $9 \cdot 7$ & 4 & 0.9 \\
\hline \multicolumn{5}{|l|}{ Hypertension } \\
\hline No & 77 & $30 \cdot 0$ & 192 & $40 \cdot 4$ \\
\hline Yes & 180 & $70 \cdot 0$ & 283 & $59 \cdot 6$ \\
\hline \multicolumn{5}{|l|}{ Diabetes } \\
\hline No & 221 & $86 \cdot 0$ & 410 & $86 \cdot 3$ \\
\hline Yes & 36 & $14 \cdot 0$ & 65 & $16 \cdot 7$ \\
\hline \multicolumn{5}{|l|}{ GDS score } \\
\hline $0-6$ & 237 & $92 \cdot 2$ & 361 & $76 \cdot 0$ \\
\hline $7-10$ & 17 & $6 \cdot 6$ & 95 & $20 \cdot 0$ \\
\hline $11-15$ & 3 & $1 \cdot 2$ & 19 & $4 \cdot 0$ \\
\hline \multicolumn{5}{|l|}{ MMSE score } \\
\hline $0-17$ & 5 & $2 \cdot 0$ & 13 & $2 \cdot 7$ \\
\hline $18-23$ & 36 & $14 \cdot 0$ & 116 & $24 \cdot 5$ \\
\hline $24-30$ & 216 & $84 \cdot 0$ & 346 & $72 \cdot 8$ \\
\hline
\end{tabular}

GDS, Geriatric Depression Scale; MMSE, Mini-Mental State Examination.

association between evidence of depression as captured by the GDS and underperformance in the MMSE, but this association does not confound the other results in the table.

With respect to nutrition, height, which integrates adequacy of nutrition throughout life, was positively associated with performance in the MMSE. Physical activity was weakly but significantly positively associated with performance in the MMSE. Controlling for total energy intake, adherence to a Mediterranean diet was very weakly and not significantly associated with MMSE score. In additional models, in which the Mediterranean diet score was alternatively substituted by each of its components, only the results concerning lipids were of note. SFA and MUFA, as well as olive oil, the principal source of lipids in a Mediterranean population, were weakly positively but not significantly associated with MMSE score. In contrast, PUFA was significantly inversely associated with performance in the MMSE and the same inverse association pattern was evident with respect to seed oils that contribute substantially to polyunsaturated lipids. Sea and seafood, the main source of long-chain PUFA, were not related to MMSE score.

We also tested the possibility of non-linear associations between MMSE score and certain dietary parameters of interest (adherence to Mediterranean diet, SFA, MUFA, PUFA, olive oil, seed oils and fish) by multivariate linear regression models each of which included observations within either the two lower or the two higher tertiles of each parameter. Negative associations with PUFA and seed oils were still present in both tested ranges for each parameter, although statistically weaker than in the whole range models. No significant associations emerged for the other parameters. Therefore, non-linearities could not be documented for any food group.

\section{Discussion}

In a sample of 732 healthy adults aged 60 years old or more at baseline, we have determined performance in the MMSE, $6 \cdot 4$ to $12 \cdot 6$ years after enrolment. After controlling for possible mutual confounding, MMSE score was found to be positively associated with years of formal education, height and physical activity and inversely associated with age, diabetes mellitus and depression, as assessed by the GDS. We also found evidence that intake of PUFA was inversely associated with performance in the MMSE and this association was accounted for, at least in part, by a similar association with seed oils.

Before discussing the individual findings, a few points concerning the adequacy of the statistical methodology followed should be noted. First, assessing several dietary parameters in alternative statistical models (multiple testing) increases the possibility of a non-existent association becoming misleadingly statistically significant. Although such an effect cannot be totally excluded, the strength of the PUFA-MMSE association, as well as the fact that seed oils (a variable overlapping but clearly distinct from PUFA) exhibited a strong association in the same direction, support the validity of the results.

Another issue of possible concern, inherent in observational studies like the present one, is the theoretical possibility of alterations in the measured outcome (MMSE score) temporally preceding and possibly affecting exposures (dietary and other variables). Although we did 
not perform the MMSE or inquire explicitly about a diagnosis of mild cognitive impairment or dementia at enrolment, a person who satisfactorily completed the long EPIC baseline questionnaire would be extremely unlikely to be suffering from significant cognitive impairment. Although a very mild cognitive impairment cannot be ruled out, such impairment would be unlikely to significantly affect diet.

The inverse association of cognitive function with age is well known ${ }^{(33)}$ and reflects the underlying association of ageing with both the distinct entities, Alzheimer's and

Table 2 Mean and standard deviation of daily intake of energy and selected nutritional components in the 732 study participants (257 men and 475 women) by gender: EPIC-Greece cohort

\begin{tabular}{|c|c|c|c|c|}
\hline \multirow[b]{2}{*}{ Variable } & \multicolumn{2}{|c|}{ Men } & \multicolumn{2}{|c|}{ Women } \\
\hline & Mean & SD & Mean & SD \\
\hline Energy intake (MJ) & 8.96 & $2 \cdot 51$ & $7 \cdot 51$ & $2 \cdot 20$ \\
\hline Energy intake (kcal) & 2141 & 607 & 1796 & 527 \\
\hline SFA (g) & $28 \cdot 8$ & $11 \cdot 4$ & $25 \cdot 4$ & $10 \cdot 2$ \\
\hline MUFA (g) & 53.5 & $18 \cdot 9$ & $46 \cdot 8$ & $17 \cdot 1$ \\
\hline PUFA (g) & $15 \cdot 3$ & $8 \cdot 2$ & $12 \cdot 5$ & $5 \cdot 9$ \\
\hline Olive oil (g) & $52 \cdot 4$ & $22 \cdot 5$ & $46 \cdot 3$ & $20 \cdot 3$ \\
\hline Seed oil (g) & $5 \cdot 7$ & $13 \cdot 2$ & $3 \cdot 4$ & $8 \cdot 5$ \\
\hline Fish \& seafo & $26 \cdot 2$ & $16 \cdot \overline{3}$ & $23 \cdot 9$ & $14 \cdot 9$ \\
\hline Mediterranean diet score & $5 \cdot 0$ & 1.7 & 4.5 & 1.6 \\
\hline
\end{tabular}

vascular dementia, and a nosologically poorly characterized mild cognitive impairment that may appear without progression to overt dementia ${ }^{(1)}$. Also well documented in the literature is the positive association of MMSE score with years of formal schooling. Although the scale was designed to detect the existence of dementing processes while having as little as possible dependence on formal schooling, it has been repeatedly shown that education does affect MMSE score through cognitive processes unrelated to dementing diseases ${ }^{(34)}$.

Among co-morbid conditions, inverse associations with cognitive function were found for diabetes mellitus and depression. Diabetes is an established risk factor for atherosclerosis and the frequently associated cerebrovascular diseases and has been found by other investigators to affect performance in the $\operatorname{MMSE}^{(35,36)}$. The links between cognitive impairment and depression are also well recognized ${ }^{(37-39)}$ and make it necessary to simultaneously assess performance in the two neuropsychiatric dimensions in order to control, as far as possible, for mutual confounding. Hypertension has been linked to cognitive impairment ${ }^{(40-42)}$. In the present data set, however, an inverse association between hypertension and MMSE score was not statistically significant, possibly because misclassification in the ascertainment of this condition is extensive.

Table 3 Multiple regression-derived differences in mean score in the Mini-Mental State Examination per indicated differences in possible predictor variables at enrolment: EPIC-Greece cohort*

\begin{tabular}{|c|c|c|c|c|}
\hline Variable & Category or increment & $B$ coefficient & $95 \% \mathrm{Cl}$ & $P$ (two-tailed) \\
\hline \multirow[t]{2}{*}{ Gender } & Male & Reference & & \\
\hline & Female & 0.44 & $-0 \cdot 30,1 \cdot 18$ & $0 \cdot 241$ \\
\hline Age & 5 years more & -0.42 & $-0 \cdot 68,-0 \cdot 16$ & 0.002 \\
\hline \multirow{2}{*}{ Marital status } & Currently married or cohabiting & Reference & & \\
\hline & Alone & -0.39 & $-0.92,0.14$ & $0 \cdot 154$ \\
\hline Years of education & 3 years more & 0.68 & $0.53,0.84$ & $<0.001$ \\
\hline Height & $5 \mathrm{~cm}$ more & 0.33 & $0.14,0.51$ & $<0.001$ \\
\hline BMI & $1 \mathrm{~kg} / \mathrm{m}^{2}$ more & 0.02 & $-0.03,0.06$ & 0.507 \\
\hline Physical activity & $3 \mathrm{MET} \times \mathrm{h}$ more & $0 \cdot 22$ & $0.02,0.42$ & 0.029 \\
\hline \multirow[t]{2}{*}{ Smoking } & Never smoked habitually & Reference & & \\
\hline & Current or ex-smoker & 0.36 & $-0.13,0.85$ & $0 \cdot 147$ \\
\hline \multirow[t]{3}{*}{ Alcohol intake } & Low & Reference & & \\
\hline & Moderate & -0.16 & $-0.82,0.49$ & 0.625 \\
\hline & High & $0 \cdot 18$ & $-0.97,1.32$ & 0.760 \\
\hline \multirow[t]{2}{*}{ Hypertension } & No & Reference & & \\
\hline & Yes & $-0 \cdot 24$ & $-0.70,0.22$ & 0.299 \\
\hline \multirow[t]{2}{*}{ Diabetes } & No & Reference & & \\
\hline & Yes & -0.71 & $-1.34,-0.08$ & 0.027 \\
\hline GDS (per scale unit) & 1 unit more & -0.09 & $-0 \cdot 16,-0.01$ & 0.025 \\
\hline Energy daily intaket & $418 \mathrm{~kJ}(100 \mathrm{kcal})$ more & -0.01 & $-0.06,0.03$ & 0.498 \\
\hline Mediterranean diet score & 1 unit more & 0.05 & $-0.09,0.19$ & 0.485 \\
\hline \multicolumn{5}{|l|}{ Alternative modelsł } \\
\hline SFA & $1 \mathrm{SD}$ more $\S$ & $0 \cdot 36$ & $-0.04,0.77$ & 0.079 \\
\hline MUFA & $1 \mathrm{sD}$ more§ & $0 \cdot 26$ & $-0 \cdot 22,0 \cdot 74$ & 0.289 \\
\hline PUFA & $1 \mathrm{SD}$ more§ & -0.40 & $-0.68,-0.13$ & 0.004 \\
\hline Olive oil & $1 \mathrm{sD}$ more§ & $0 \cdot 20$ & $-0 \cdot 11,0.51$ & 0.204 \\
\hline Seed oil & 1 SD more $\S$ & -0.34 & $-0.56,-0.12$ & 0.002 \\
\hline Fish \& seafood & $1 \mathrm{SD}$ more§ & 0.05 & $-0 \cdot 17,0 \cdot 27$ & 0.649 \\
\hline
\end{tabular}

GDS, Geriatric Depression Scale.

${ }^{*} n 732$.

tInclusion of the energy daily intake variable serves as statistical method of energy adjustment.

$\ddagger$ In each additional model, one dietary variable of those listed below was alternatively substituted for Mediterranean diet score.

$\S$ Gender-specific standard deviation. 
Height was significantly positively associated with the score. It appears that adequate nutrition in earlier life ${ }^{(43)}$, which is likely reflected in taller stature, has minor but nevertheless long-lasting effects on cognition. Similar associations have been reported previously by other investigators $^{(44-46)}$. In contrast to height, no associations were found with weight or $\mathrm{BMI}^{(47,48)}$. The relationship between BMI and cognitive function is complex. Obesity, acting indirectly through atherosclerotic disease, may pose a risk for vascular dementia, but BMI decline rates also have been noted in the early stages of dementing conditions $^{(48)}$.

We have also found a strong positive association between physical activity at enrolment and MMSE score some 6-13 years later. This temporal relationship supports a protective role of physical activity against cognitive impairment. Our finding is in line with several other cohort studies reporting better cognitive function with physical $\operatorname{activity}^{(49,50)}$. Nevertheless, physical activity is also associated with mental and social activities and the complexities of these associations hinder the determination of exact aetiological relationships ${ }^{(49)}$. Recent studies with animal models have shown exercise to increase levels of brainderived neurotrophic factor and other growth factors, as well as to mobilize those gene expression profiles that could stimulate neurogenesis, resistance to brain insult, mental performance and brain plasticity ${ }^{(51)}$.

We detected no significant association between smoking and MMSE score. Several studies have shown an adverse effect of smoking on cognition ${ }^{(52,53)}$, possibly attributable to the well-known effect of smoking on vascular disease. Others, especially case-control studies, have indicated a possible protective effect ${ }^{(54,55)}$, hypothesized to be mediated at least in part by the cholinergic effects of nicotine ${ }^{(56)}$. Of note, smoking appears to be associated with reduced risk of one of the lesser causes of dementia, Parkinson's disease $^{(57)}$, with unclear mechanisms.

Adherence to the Mediterranean diet has been inversely associated with risk for Alzheimer's disease in a US population $^{(58)}$. In the present investigation, only a very weak protective trend of this dietary pattern on MMSE score was seen, perhaps in part due to our relatively small sample. Nevertheless, the studies are not directly comparable, because the populations have important differences (notably multiracial composition in the US study), the measured outcomes are not the same (MMSE $v$. diagnosis of dementia), and the dietary composition of the Mediterranean diet is significantly different between the US and Greek cohorts, mainly with regard to lipids ${ }^{(59)}$.

Consumption of MUFA has recently been found to be apparently protective against age-related cognitive decline in a large Italian cohort ${ }^{(60)}$. In line with this result, we did detect a trend for a protective effect of MUFA and their main source, olive oil. It should be noted that although MUFA are part of the Mediterranean diet score, their borderline association with MMSE score was not sufficient to generate a detectable association of the overall Mediterranean diet score with MMSE score.

Consumption of PUFA, on the other hand, was inversely associated with cognitive function and the association became evident after controlling for years of education, because the latter variable is positively associated with PUFA, thus generating negative confounding. An inverse association was also observed with seed oils, which contribute substantially to PUFA. On the other hand, no association was seen with fish and seafood, which are also major contributors to PUFA. Studies assessing total PUFA intake in relation to cognitive function have generated conflicting results. In a large Italian cohort, it was found that the MMSE performance was positively correlated with high PUFA intake ${ }^{(60-62)}$, but no inferences were made about the differential impact, if any, of categories within the large PUFA group (seed oils, fish oils). In the Chicago Health and Aging Project (CHAP), PUFA were associated with a slower cognitive decline, an association that was attributed mainly to their high content of vitamin $\mathrm{E}^{(63)}$. Among the PUFA-containing food groups, seed oils have a high content of n-6 fatty acids, mainly linoleic acid. High linoleic acid intake was associated with cognitive impairment in the Zutphen Elderly Study ${ }^{(64)}$, in line with the present results, and a decline in MMSE score has been associated with higher erythrocyte membrane content of $n$ - 6 PUFA $^{(65)}$. On the other hand, a trend towards a protective effect of $n-6$ PUFA against Alzheimer's disease was found in the CHAP study ${ }^{(66)}$, whereas no effect of $n-6$ PUFA on risk of dementia was seen in the Rotterdam Study ${ }^{(67)}$. Fish and seafood has a high content of long-chain $n$ - 3 fatty acids; in some although not all studies they have been positively associated with cognitive performance ${ }^{(64,68-71)}$. Such an association, however, was not seen in the present study.

Further work employing detailed information on the lipid composition of consumed foods, large sample populations, and long follow-up periods is clearly needed to identify whether and which PUFA compounds affect cognitive function. At this stage, it would be fair to conclude that long-chain $n-3$ fatty acids are possibly beneficial, whereas n-6 fatty acids may have an adverse effect on cognitive performance. The mechanisms by which high seed oil consumption might impair cognitive function are unknown. Nevertheless, a diet rich in n-6 PUFA may increase the susceptibility of LDL-cholesterol to oxidation, thus promoting atherogenesis ${ }^{(72)}$. Dyslipidaemia and atherogenesis can then promote microvascular cerebral disease and, possibly, Alzheimer's disease as well.

The strengths of the present investigation are its prospective nature, the general population study base, the use of validated instruments, the quantitative assessment of seed oil consumption, and examination of and control for several covariates with potential confounding influence. A significant limitation is the lack of cognitive assessment at baseline, resulting in inability to estimate 
patterns of MMSE score decline. Other limitations include the relatively small population size, as well as the inherent difficulty of observational studies to conclusively document the causal nature and the directionality of an association.

In conclusion, in a prospective study of a general population cohort, we have found evidence that early life factors as reflected in stature, after controlling for current socio-economic status and dietary intakes, are predictive of cognitive function several decades later. Physical activity was positively associated with cognitive function in this group of elderly persons and the prospective study design favours, although it does not conclusively document, a causal effect. Finally, we have found evidence that, in contrast to other lipid categories that appear to be neutral or only weakly protective with respect to cognitive function, $n-6$ PUFA may have an adverse effect on performance on the MMSE scale. The latter finding has been reported in other prospective investigations as well, but the present study is the first one to detect this effect in a Mediterranean population. This lipid category appears to deserve focused attention in future investigations for possible confirmation or refutation.

\section{Acknowledgements}

Sources of funding: The study was supported by the Europe Against Cancer Programme of the European Commission, the Greek Ministry of Health, the Greek Ministry of Education, an unrestricted grant to the University of Athens in honour of 'Vasilios and Nafsika Tricha' and the Hellenic Health Foundation. The ILIDA project was co-funded by the European Social Fund and National Resources - (EPEAEK II) PYTHAGORAS.

Conflict of interest: There is no conflict of interest for any of the authors of the present manuscript.

Authorship responsibilities: T.P. took the lead in the development of several aspects of the manuscript. P.S. contributed to the data collection and processing. A.K. and D.V. were the clinical consultants for dementia and the neurological aspects of the present paper. D.T. was the epidemiology consultant. A.T. is the principal investigator of the EPIC-Greece project and supervised all aspects of this project. All authors contributed to the writing of the manuscript.

\section{References}

1. Gauthier S, Reisberg B, Zaudig M et al. (2006) Mild cognitive impairment. Lancet 367, 1262-1270.

2. Moise P, Scwarzinger M, Um M-Y \& Dementia Experts' Group (2004) Dementia Care in 9 OECD Countries: A Comparative Analysis. OECD Health Working Papers no. 13, DELSA/ELSA/WD/HEA/(2004)4. http://www.oecd.org/ dataoecd/10/52/33661491.pdf

3. World Health Organization \& Tufts University School of Nutrition and Policy (2002) Keep fit for life. Meeting the nutritional needs of older persons. http://whqlibdoc.who. int/publications/9241562102_annexes.pdf

4. Hou CE, Yaffe K, Perez-Stable EJ \& Miller BL (2006) Frequency of dementia etiologies in four ethnic groups. Dementia Geriatr Cogn Dis 22, 42-47.

5. Jellinger KA (2006) Clinicopathological analysis of dementia disorders in the elderly - an update. J Alzheimers Dis $\mathbf{9}$, 61-70.

6. Kalaria RN (2003) Vascular factors in Alzheimer's disease. Int Psychogeriatr 15, Suppl. 1, 47-52.

7. Napoli C \& Palinski W (2005) Neurodegenerative diseases: insights into pathogenic mechanisms from atherosclerosis. Neurobiol Aging 26, 293-302.

8. Nash DT \& Fillit H (2006) Cardiovascular disease risk factors and cognitive impairment. Am J Cardiol 97, $1262-1265$.

9. Stampfer MJ (2006) Cardiovascular disease and Alzheimer's disease: common links. J Intern Med 260, 211-223.

10. White L \& Launer L (2006) Relevance of cardiovascular risk factors and ischemic cerebrovascular disease to the pathogenesis of Alzheimer disease: a review of accrued findings from the Honolulu-Asia Aging Study. Alzheimer Dis Assoc Disord 20, S79-S83.

11. Espino DV, Lichtenstein MJ, Palmer RF \& Hazuda HP (2001) Ethnic differences in Mini-Mental State Examination (MMSE) scores: where you live makes a difference. $\mathrm{J} \mathrm{Am}$ Geriatr Soc 49, 538-548.

12. Ishizaki J, Meguro K, Ambo H, Shimada M, Yamaguchi S, Hayasaka C, Komatsu H, Sekita Y \& Yamadori A (1998) A normative, community-based study of Mini-Mental State in elderly adults: the effect of age and educational level. J Gerontol B Psychol Sci Soc Sci 53, P359-P363.

13. Monsch AU, Foldi NS, Ermini-Funfschilling DE, Berres M, Taylor KI, Seifritz E, Stahelin HB \& Spiegel R (1995) Improving the diagnostic accuracy of the Mini-Mental State Examination. Acta Neurol Scand 92, 145-150.

14. Stewart R, Johnson J, Richards M, Brayne C \& Mann A (2002) The distribution of Mini-Mental State Examination scores in an older UK African-Caribbean population compared to MRC CFA study norms. Int $J$ Geriatr Psychiatry 17, 745-751.

15. Fountoulakis KN, Tsolaki M, Paulopoulos H \& Kazis A (2002) Validation of the epidemiological dementia index in geriatric outpatients. Int Psychogeriatr 12, 195-208.

16. de Craen AJ, Heeren TJ \& Gussekloo J (2003) Accuracy of the 15-item Geriatric Depression Scale (GDS-15) in a community sample of the oldest old. Int $J$ Geriatr Psychiatry 18, 63-66.

17. Haller J, Weggemans RM, Ferry M \& Guigoz Y (1996) Mental health: Mini-Mental State Examination and Geriatric Depression Score of elderly Europeans in the SENECA study of 1993. Eur J Clin Nutr 50, Suppl. 2, S112-S116.

18. Osborn DP, Fletcher AE, Smeeth L, Stirling S, Nunes M, Breeze E, Siu-Woon Ng E, Bulpitt CJ, Jones D \& Tulloch A (2002) Geriatric Depression Scale scores in a representative sample of 14545 people aged 75 and over in the United Kingdom: results from the MRC Trial of Assessment and Management of Older People in the Community. Int $J$ Geriatr Psychiatry 17, 375-382.

19. Yesavage JA, Brink TL, Rose TL, Lum O, Huang V, Adey M \& Leirer VO (1982) Development and validation of a geriatric depression screening scale: a preliminary report. J Psychiatr Res 17, 37-49.

20. Fountoulakis KN, Tsolaki M, Iacovides A, Yesavage J, O'Hara R, Kazis A \& Ierodiakonou C (1999) The validation of the short form of the Geriatric Depression Scale (GDS) in Greece. Aging (Milano) 11, 367-372.

21. Trichopoulou A, Costacou T, Bamia C \& Trichopoulos D (2003) Adherence to a Mediterranean diet and survival in a Greek population. New Engl J Med 348, 2599-2608. 
22. Bingham S \& Riboli E (2004) Diet and cancer - the European Prospective Investigation into Cancer and Nutrition. Nat Rev Cancer 4, 206-215.

23. Riboli E, Hunt KJ, Slimani N et al. (2002) European Prospective Investigation into Cancer and Nutrition (EPIC): study populations and data collection. Public Health Nutr 5, 1113-1124.

24. Gnardellis C, Trichopoulou A, Katsouyanni K, Polychronopoulos E, Rimm EB \& Trichopoulos D (1995) Reproducibility and validity of an extensive semiquantitative food frequency questionnaire among Greek school teachers. Epidemiology 6, 74-77.

25. Goldbohm RA, van't Veer P, van den Brandt PA, van't Hof MA, Brants HA, Sturmans F \& Hermus RJ (1995) Reproducibility of a food frequency questionnaire and stability of dietary habits determined from five annually repeated measurements. Eur J Clin Nutr 49, 420-429.

26. Willett WC, Sampson L, Browne ML, Stampfer MJ, Rosner B, Hennekens CH \& Speizer FE (1988) The use of a selfadministered questionnaire to assess diet four years in the past. Am J Epidemiol 127, 188-199.

27. Trichopoulou A \& Georga K (editors) (2004) Composition Tables of Simple and Composite Foods. Athens: Parisianos.

28. Willett W \& Stampfer M (1998) Implications of total energy intake for epidemiological analyses. In Nutritional Epidemiology, 2nd ed., pp. 273-301 [W Willett, editor]. New York: Oxford University Press.

29. Trichopoulou A, Gnardellis C, Lagiou A, Benetou V \& Trichopoulos D (2000) Body mass index in relation to energy intake and expenditure among adults in Greece. Epidemiology 11, 333-336.

30. Ainsworth BE, Haskell WL, Leon AS, Jacobs DR Jr, Montoye HJ, Sallis JF \& Paffenbarger RS Jr (1993) Compendium of physical activities: classification of energy costs of human physical activities. Med Sci Sports Exerc 25, 71-80.

31. Crum RM, Anthony JC, Bassett SS \& Folstein MF (1993) Population-based norms for the Mini-Mental State Examination by age and educational level. JAMA 269 , 2386-2391.

32. Folstein MF, Folstein SE \& McHugh PR (1975) 'Mini-mental state'. A practical method for grading the cognitive state of patients for the clinician. J Psychiatr Res 12, 189-198.

33. Park HL, O'Connell JE \& Thomson RG (2003) A systematic review of cognitive decline in the general elderly population. Int J Geriatr Psychiatry 18, 1121-1134.

34. Tombaugh TN \& McIntyre NJ (1992) The Mini-Mental State Examination: a comprehensive review. J Am Geriatr Soc 40, 922-935.

35. Pasquier F, Boulogne A, Leys D \& Fontaine P (2006) Diabetes mellitus and dementia. Diabetes Metab 32, 403-414.

36. van den Berg E, Kessels RP, Kappelle LJ, de Hann EH \& Biessels GJ (2006) Type 2 diabetes, cognitive function and dementia: vascular and metabolic determinants. Drugs Today (Barc) 42, 741-754.

37. Ganguli M, Du Y, Dodge HH, Ratcliff GG \& Chang CC (2006) Depressive symptoms and cognitive decline in late life: a prospective epidemiological study. Arch Gen Psychiatry 63, 153-160.

38. Green RC, Cupples LA, Kurz A et al. (2003) Depression as a risk factor for Alzheimer disease: the MIRAGE Study. Arch Neurol 60, 753-759.

39. Lichtenberg PA, Ross T, Millis SR \& Manning CA (1995) The relationship between depression and cognition in older adults: a cross-validation study. J Gerontol B Psychol Sci Soc Sci 50, P25-P32.

40. Cervilla JA, Prince M, Joels S, Lovestone S \& Mann A (2000) Long-term predictors of cognitive outcome in a cohort of older people with hypertension. Br J Psychiatry 177, 66-71.
41. Forette F, Seux ML, Staessen JA et al. (1998) Prevention of dementia in randomised double-blind placebo-controlled Systolic Hypertension in Europe (Syst-Eur) trial. Lancet 352, 1347-1351.

42. Skoog I \& Gustafson D (2006) Update on hypertension and Alzheimer's disease. Neurol Res 28, 605-611.

43. Gunnell D (2002) Can adult anthropometry be used as a 'biomarker' for prenatal and childhood exposures? Int J Epidemiol 31, 390-394.

44. Abbott RD, White LR, Ross GW, Petrovitch H, Masaki KH, Snowdon DA \& Curb JD (1998) Height as a marker of childhood development and late-life cognitive function: the Honolulu-Asia Aging Study. Pediatrics 102, 602-609.

45. Beeri MS, Davidson M, Silverman JM, Noy S, Schmeidler J \& Goldbourt U (2005) Relationship between body height and dementia. Am J Geriatr Psychiatry 13, 116-123.

46. Jeong SK, Kim JM, Kweon SS, Shin MH, Seo MW \& Kim YH (2005) Does arm length indicate cognitive and functional reserve? Int J Geriatr Psychiatry 20, 406-412.

47. Buchman AS, Schneider JA, Wilson RS, Bienias JL \& Bennett DA (2006) Body mass index in older persons is associated with Alzheimer disease pathology. Neurology 67, 1949-1954.

48. Gustafson D (2006) Adiposity indices and dementia. Lancet Neurol 5, 713-720.

49. Fratiglioni L, Paillard-Borg S \& Winblad B (2004) An active and socially integrated lifestyle in late life might protect against dementia. Lancet Neurol 3, 343-353.

50. Lautenschlager NT \& Almeida OP (2006) Physical activity and cognition in old age. Curr Opin Psychiatry 19, 190-193.

51. Cotman CW \& Berchtold NC (2002) Exercise: a behavioral intervention to enhance brain health and plasticity. Trends Neurosci 25, 295-301.

52. Juan D, Zhou DH, Li J, Wang JY, Gao C \& Chen M (2004) A 2-year follow-up study of cigarette smoking and risk of dementia. Eur J Neurol 11, 277-282.

53. Ott A, Andersen K, Dewey ME et al. (2004) Effect of smoking on global cognitive function in nondemented elderly. Neurology 62, 920-924.

54. Almeida OP, Hulse GK, Lawrence D \& Flicker L (2002) Smoking as a risk factor for Alzheimer's disease: contrasting evidence from a systematic review of case-control and cohort studies. Addiction 97, 15-28.

55. Letenneur L, Larrieu S \& Barberger-Gateau P (2004) Alcohol and tobacco consumption as risk factors of dementia: a review of epidemiological studies. Biomed Pharmacother 58, 95-99.

56. Sabbagh MN, Lukas RJ, Sparks DL \& Reid RT (2002) The nicotinic acetylcholine receptor, smoking, and Alzheimer's disease. J Alzheimers Dis 4, 317-325.

57. Allam MF, Campbell MJ, Hofman A, Del Castillo AS \& Fernandez-Crehuet Navajas R (2004) Smoking and Parkinson's disease: systematic review of prospective studies. Mov Disord 19, 614-621.

58. Scarmeas N, Stern Y, Tang MX, Mayeux R \& Luchsinger JA (2006) Mediterranean diet and risk for Alzheimer's disease. Ann Neurol 59, 912-921.

59. Solfrizzi V, Capurso C \& Panza F (2006) Adherence to a Mediterranean dietary pattern and risk of Alzheimer's disease. Ann Neurol 60, 620.

60. Solfrizzi V, Colacicco AM, D'Introno A, Capurso C, Torres F, Rizzo C, Capurso A \& Panza F (2006) Dietary intake of unsaturated fatty acids and age-related cognitive decline: a $8 \cdot 5$-year follow-up of the Italian Longitudinal Study on Aging. Neurobiol Aging 27, 1694-1704.

61. Solfrizzi V, Colacicco AM, D'Introno A, Capurso C, Del Parigi A, Capurso SA, Argentieri G, Capurso A \& Panza F (2006) Dietary fatty acids intakes and rate of mild cognitive impairment. The Italian Longitudinal Study on Aging. Exp Gerontol 41, 619-627. 
62. Solfrizzi V, D'Introno A, Colacicco AM, Capurso C, Del Parigi A, Capurso S, Gadaleta A, Capurso A \& Panza F (2005) Dietary fatty acids intake: possible role in cognitive decline and dementia. Exp Gerontol 40, 257-270.

63. Morris MC, Evans DA, Bienias JL, Tangney CC \& Wilson RS (2004) Dietary fat intake and 6-year cognitive change in an older biracial community population. Neurology $\mathbf{6 2}$, 1573-1579.

64. Kalmijn S, Feskens EJ, Launer LJ \& Kromhout D (1997) Polyunsaturated fatty acids, antioxidants, and cognitive function in very old men. Am J Epidemiol 145, 33-41.

65. Heude B, Ducimetiere P \& Berr C (2003) Cognitive decline and fatty acid composition of erythrocyte membranes The EVA Study. Am J Clin Nutr 77, 803-808.

66. Morris MC, Evans DA, Bienias JL, Tangney CC, Bennett DA, Aggarwal N, Schneider J \& Wilson RS (2003) Dietary fats and the risk of incident Alzheimer disease. Arch Neurol 60 , 194-200.

67. Engelhart MJ, Geerlings MI, Ruitenberg A, Van Swieten JC, Hofman A, Witteman JC \& Breteler MM (2002) Diet and risk of dementia: does fat matter?: The Rotterdam Study. Neurology 59, 1915-1921.
68. Issa AM, Mojica WA, Morton SC, Traina S, Newberry SJ, Hilton LG, Garland RH \& Maclean CH (2006) The efficacy of omega- 3 fatty acids on cognitive function in aging and dementia: a systematic review. Dementia Geriatr Cogn Disord 21, 88-96.

69. Kalmijn S, Launer LJ, Ott A, Witteman JC, Hofman A \& Breteler MM (1997) Dietary fat intake and the risk of incident dementia in the Rotterdam Study. Ann Neurol 42, 776-782.

70. Kalmijn S, van Boxtel MP, Ocke M, Verschuren WM, Kromhout D \& Launer LJ (2004) Dietary intake of fatty acids and fish in relation to cognitive performance at middle age. Neurology 62, 275-280.

71. Morris MC, Evans DA, Bienias JL, Tangney CC, Bennett DA, Wilson RS, Aggarwal N \& Schneider J (2003) Consumption of fish and $n$-3 fatty acids and risk of incident Alzheimer disease. Arch Neurol 60, 940-946.

72. Reaven PD, Grasse BJ \& Tribble DL (1994) Effects of linoleate-enriched and oleate-enriched diets in combination with alpha-tocopherol on the susceptibility of LDL and LDL subfractions to oxidative modification in humans. Arterioscler Thromb Vasc Biol 14, 557-566. 